\title{
Acute Abdominal Pain in Childhood, with Special Reference to Cases not due to Acute Appendicitis*
}

\author{
PETER F. JONES, $†$ M.CHIR., F.R.C.S.
}

Gummary : Appendicitis is not the only common cause $\checkmark$ of acute abdominal pain in childhood. Almost equally common is an acute episode which in its early stages resembles acute appendicitis but which subsides without treatment in $\mathbf{2 4}$ to $\mathbf{4 8}$ hours. The clinical features of this syndrome are contrasted with those of appendicitis. The two conditions cannot always be distinguished on clinical grounds, leading to admission to hospital for observation and the finding of a normal appendix in $14 \%$ of operations for suspected appendicitis. Reasons are given for abandoning attempts to diagnose acute mesenteric adenitis at the bedside.

\section{Introduction}

Acute appendicitis in childhood rightly receives much attention because it is a potentially lethal condition. It is, however, not the only common cause of acute abdominal pain in childhood, and the purpose of this paper is to examine this wider subject.

The Royal Aberdeen Hospital for Children admits virtually all paediatric abdominal emergencies occurring in a population of some 400,000 people. Whenever the family doctor requests an emergency admission the child is accepted and is admitted direct to the ward. A previous paper (Winsey and Jones, 1967) described a detailed survey of every case of acute abdominal pain admitted to this hospital during 1965 . It showed that of cases admitted to surgical wards roughly half were treated surgically, $37 \%$ having acute appendicitis, $7 \%$ some other major surgical conditions such as intussusception, and in $6 \%$ a normal appendix was removed. In the nonsurgical group $15 \%$ had an acute medical disease such as pneumonia or pyelitis, but $35 \%$ showed a steady spontaneous improvement of their illness after admission and left hospital in 48 to 72 hours.

It seemed surprising that so many children admitted with a suspected acute surgical abdominal lesion should recover spontaneously and quickly, therefore it was decided to continue the survey for a further two years, 1966 and 1967. The method of recording previously used was continued.

\section{Findings}

During the three years 785 children up to 12 years of age were admitted to the hospital as suspected cases of acute appendicitis and treated without mortality. The final outcome in these 785 children is set out in Table I.

It will be seen that the numbers in each group in each year are comparable, though there is no known factor responsible for the appreciable increase in acute appendicitis during 1967.

In particular it will be noted that about $40 \%$ of those admitted with suspected acute appendicitis settled without specific treatment. When sent into hospital these children

\footnotetext{
* Based on a paper read to the Annual Meeting of the British Association of Paediatric Surgeons, Liverpool, July 1968.
}

t Consultant Surgeon, Royal Aberdeen Hospital for Children, Aberdeen. all had symptoms and/or signs which worried their family doctor (and in some cases a surgeon called to the home on a domiciliary consultation). Analysis of age shows few patients below 5 years $(16 \%)$ and an even incidence throughout the seven school years (with a slight preponderance at 9 years of age). Boys (55\%) were slightly more affected than girls $(45 \%)$, and this was seen at all ages.

\begin{tabular}{|c|c|c|c|c|c|}
\hline Outcome of Admission & & 1965 & 1966 & 1967 & Total \\
\hline $\begin{array}{l}\text { Appendicectomies: } \\
\text { Acute appendicitis found } \\
\text { Normal appendix found: }\end{array}$ & .. & 114 & 121 & 163 & \\
\hline Mesenteric adenitis & $\because$ & $\begin{array}{l}11 \\
10\end{array}$ & $\begin{aligned} 11 \\
9\end{aligned}$ & $\begin{array}{r}20 \\
3\end{array}$ & $\left.\begin{array}{l}42 \\
22\end{array}\right\} \begin{array}{c}14 \% \text { of } \\
\text { laparotomies }\end{array}$ \\
\hline $\begin{array}{l}\text { No operation: } \\
\text { Spontaneous recovery }\end{array}$ & .. & 119 & 100 & 104 & 323 \\
\hline Total & .. & 254 & 241 & 290 & 785 \\
\hline
\end{tabular}

A study of the clinical picture in the 323 children who settled spontaneously confirms the description of this group given by Winsey and Jones (1967). Pain is usually felt centrally $(70 \%)$, much less often in the right iliac fossa $(13 \%)$. Pain only rarely shifts to the right iliac fossa, and the patient can move without aggravating the pain. Tenderness is usually present in the right iliac fossa initially (this is the main reason for the high admission rate), but it soon relents, and is found in only half the patients by the time they are admitted. Rebound tenderness is not elicited and muscle guarding is most unusual.

When set out in this way this condition is clearly distinguishable from acute appendicitis (Table II), but these points are not always so clear-cut in the individual case, more especially in the early hours of the illness. It is the steady amelioration of symptoms and signs seen when the patient is re-examined at intervals of a few hours which enables this syndrome of acute non-specific abdominal pain of childhood to be identified : it is a diagnosis which can firmly be made only in retrospect.

TABLE II.-Comparison of Incidence of Symptoms and Signs of Most Assistance in Distinguishing Acute Appendicitis from Acute Nonspecific Abdominal Pain of Childhood

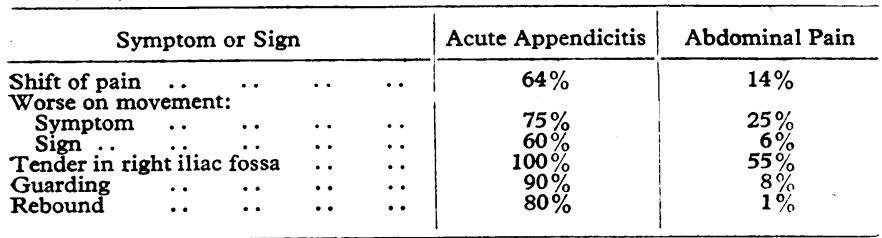

It seemed wise to look further into the subsequent history of all these children, to see whether any later event might shed light on the reason for the original admission. Seven out of the 323 children were readmitted up to June 1968 with surgical abdominal disease- - six had acute appendicitis and one had an intussusception of Meckel's diverticulum. With the benefit of hindsight it is possible to say that three of the six children probably had acute appendicitis on their first admission but in each case it was at a stage when it was clinically improving. 
Another nine children were readmitted with abdominal pain which settled quickly, one child was readmitted with a urinary infection (which was not present on the first admission) and another was admitted with torsion of a normally sited left testicle. There were no other relevant readmissions.

The other main group comprised 462 children who had an appendicectomy because acute appendicitis was either confidently diagnosed or strongly suspected on the basis of one or more examinations after admission.

In 398 children an acutely inflamed appendix was removed, the diagnosis being confirmed by naked-eye and histological examination. The clinical features of this group were described in detail in the previous paper.

In 64 children the appendix was normal when exposed at operation. In 42 of these children acute mesenteric adenitis was found. In six cases various other conditions, such as haemorrhage into an ovarian cyst, threadworms in the appendix, or suppurating mesenteric nodes, were thought to be the cause of the illness. In the remaining 16 children laparotomy did not yield any recognizable cause for their pain.

Acute mesenteric adenitis caused considerable confusion. The histories of these 42 patients were examined in an attempt to elucidate this. In one-quarter of them there was a shift of pain from the centre of the abdomen to the right iliac fossa, one-third found it painful to move about the bed, and another one-third had rebound tenderness. Half the patients had guarding as well as tenderness in the right iliac fossa, and in nearly half these signs became more pronounced while these subjects were observed in the ward. These were features characteristic of acute appendicitis, and it was clearly necessary to open these patients. Nearly half of them had the central colicky abdominal pain which Aird (1945) considered to be typical of acute mesenteric adenitis, but this in itself did not allow physical signs strongly suggestive of appendicitis to be overlooked. In only 4 of the 42 patients were cervical lymph nodes palpably enlarged.

\section{Discussion}

The analysis of a large group of children admitted to hospital with acute abdominal pain shows that in the first hours of the illness it can be difficult to distinguish those who have acute appendicitis from those who have transient non-specific abdominal pain. Acute abdominal pain and tenderness in the right iliac fossa are seen in both conditions. The difficulties of diagnosing atypical acute appendicitis are widely known and as a consequence considerable numbers of children with nonspecific abdominal pain are referred to hospital-roughly 20,000 every year in Great Britain, if experience in Aberdeen is representative of practice throughout the country.

The two groups can to a large extent be separated by the practice of active observation, in which clinical examination is repeated every few hours until a diagnosis is reached. The more serious cases of appendicitis are evident on the first examination and their treatment is not delayed by this practice. In the other cases no harm comes from observation for a few hours, and often a very much more satisfactory examination is possible on a second visit. Repetition of the examination may be possible in the child's home, but circumstances or distance may make this unwise and the child is then referred to hospital at the first visit.

In Aberdeen some $40 \%$ of children referred to hospital with suspected acute appendicitis are found to improve spontaneously within hours or at most a day or so. The pathological condition which causes the acute and definite pain and tenderness these children show remains obscure. Constipation is often incriminated, but it was not noticeable in more than a small minority $(8 \%)$. Serious consideration must be given to the possibility that these children have mild appendicitis. However, only six were readmitted with acute appendicitis over three and a half years, and the policy throughout was to advise operation whenever doubt regarding the diagnosis persisted. It seems unlikely that many acutely inflamed appendices were not removed.

Some of the children may have had acute mesenteric adenitis, but there can be no certainty about this. Our experience with this disease must cast great doubt on whether it is wise or safe to attempt to diagnose it at the bedside. We fully endorse the conclusion of Potts (1959), who stated : "Acute mesenteric lymphadenitis so closely mimics acute appendicitis that differentiation is impossible. If you make a diagnosis of acute mesenteric lymphadenitis it is wise to advise appendectomy to see whether you are right."

Even with the experience and investigative resources available in hospital, and the opportunity to re-examine at intervals, it is not possible to make a certain division between those children needing and those not needing an operation. Decision has to be based on continuing clinical assessment, and in this series $14 \%$ of the children thought to need operation were found to have a normal appendix.

Information about the number of normal appendices removed in operations for suspected acute appendicitis is not always given, but some papers in which this information is provided are summarized in Table III. The figure of $14 \%$ for the proportion of normal appendices seems to be the commonest and the lowest figure quoted. It is also associated with the least mortality, so it does not appear that a greater readiness to explore the doubtful case will necessarily lower mortality.

TABLE III.-Incidence of Finding of Normal Appendox at Operation for

\begin{tabular}{|c|c|c|c|c|c|c|}
\hline \multirow[t]{2}{*}{ Authors } & \multirow[t]{2}{*}{ City } & \multirow[t]{2}{*}{$\begin{array}{c}\text { Age Range } \\
\text { in Years }\end{array}$} & \multirow{2}{*}{$\begin{array}{c}\text { Total } \\
\text { Appendi- } \\
\text { cectomies }\end{array}$} & \multicolumn{2}{|c|}{$\begin{array}{c}\text { Normal } \\
\text { Appendices } \\
\text { Removed }\end{array}$} & \multirow{2}{*}{$\begin{array}{c}\text { Mortality } \\
(\%)\end{array}$} \\
\hline & & & & No. & $\%$ & \\
\hline $\begin{array}{l}\text { Boles et al. } \\
\text { (1959) } \\
\text { Brown (1956) } \\
\text { Present series } \\
\text { McLauthlin } \\
\text { and Packard } \\
\text { (1961) } \\
\text { Barnes et al. } \\
\text { (1962) .. }\end{array}$ & 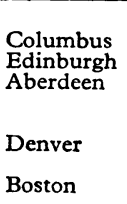 & $\begin{array}{l}\text { Up to } 12 \\
\text { Up to } 12 \\
\text { Up to } 12 \\
\text { Up to } 14 \\
\text { Adults }\end{array}$ & $\begin{array}{r}474 \\
7,820\end{array}$ & $\begin{array}{r}107 \\
1,978\end{array}$ & $\begin{array}{l}22 \\
25\end{array}$ & $\begin{array}{l}0.1 \\
0.14 \\
0 \\
0.86 \\
1.0\end{array}$ \\
\hline
\end{tabular}

Howie (1968a) suggested that a radical approach, with removal of the appendix in four out of every five patients admitted with suspected appendicitis, will lead to more acutely inflamed appendices being removed and will produce lowering of morbidity after discharge. The approach in this hospital has been radical in so far as operation has always been performed whenever doubt persisted about the existence of acute appendicitis. This has led to three appendicectomies being done among every five patients admitted-a rate which Howie considers to indicate a "conservative approach." However, this series was composed entirely of children, while Howie studied no patients under 12 years. It may well be that acute non-specific abdominal pain in childhood is a different condition, does not imply there is any appendicular infection, and can generally be identified by its tendency toward rapid spontaneous resolution. Certainly the readmission rate among our young patients is very low-about $4 \%$-and we have not experienced any indication for the planned appendicectomy for recurrent abdominal pain which Howie (1968b) described among his patients who were treated conservatively.

However, nothing should detract from the support which Howie's work gives to the policy of operation when doubt persists about the presence of acute appendicitis; this must be strongly endorsed. 
It may at first sight seem to be unsatisfactory that 14 out of every 100 children operated on for suspected appendicitis will have a normal appendix and that two out of every five children admitted with this diagnosis will recover without treatment. These figures express, however, a widespread concern about the difficulty of diagnosing some cases of acute appendicitis in childhood. If the mortality of acute appendicitis is now very low, it must not be forgotten that a number of children still reach hospital gravely ill with peritonitis and survive only after much discomfort, hard work, and anxiety.

Readiness to admit and to operate on the doubtful case is the price we rightly pay for the earlier solution of the diag- nostic problems which acute appendicitis in childhood will continue to set.

$$
\text { REFERENCES }
$$

Aird, I. (1945). Brit. med. f., 2, 680.

Barnes, B. A., Behringer, G. E., Wheelock, F. C., and Wilkins, E. W. (1962) O. Amer. med. Ass., 180, 122.

Boles, E. T., Iseton, R. J., and Clatworthy, H. W. (1959). Arch. Surg., 79, 447 .

Brown, J. J. M. (1956). F. roy. Coll. Surg. Edinb., 1, 268.

Howie, J. G. R. (1968a). Lancet, 1, 1365 .

Howie, J. G. R. (1968b). Scot. med. Ұ., 13, 68.

McLauthlin, C. H., and Packard, G. B. (1961). Amer. F. Surg., 101, 619.

Potts, W. J. (1959). The Surgeon and the Child. Philadelphia.

Winsey, H. S., and Jones, P. F. (1967). Brit. med. F., 1, 653 .

\title{
Measurement of Digoxin in Plasma and its use in Diagnosis of Digoxin Intoxication
}

\author{
D. G. GRAHAME-SMITH,* M.B., PH.D., M.R.C.P.; M. S. EVEREST, $\dagger$ M.B., B.S., M.R.C.P.
}

\begin{abstract}
Cummary : A method for measuring the plasma-digoxin concentration uses the measurement of its inhibitory effect on ${ }^{86} \mathbf{R b}$ uptake by human red cells in vitro. Patients receiving digoxin in whom there was no clinical evidence of digoxin intoxication had plasma digoxin concentrations ranging from 0.8 to $4.5 \mathrm{~m} \mu \mathrm{g} . / \mathrm{ml}$. Patients presenting with convincing clinical evidence of digoxin intoxication had plasma digoxin concentrations ranging from 4 to greater than $8 \mathrm{~m} \mu \mathrm{g} . / \mathrm{ml}$. It is suggested that the plasma digoxin concentration may be used as an aid in the diagnosis of digoxin intoxication.
\end{abstract}

\section{Introduction}

Cardiac glycosides inhibit the uptake of potassium by human red cells (Glynn, 1957). Love and Burch (1953) suggested the use of a rubidium isotope, ${ }^{88} \mathrm{Rb}$, as a tracer for potassium in such metabolic studies because of its more convenient half-life $\left({ }^{88} \mathrm{Rb}, 19.5\right.$ days $;{ }^{42} \mathrm{~K}, 12.4$ hours). Lowenstein (1965) and Lowenstein and Corrill (1966) studied the inhibiting effect of plasma and extracts of plasma from patients receiving digoxin and digitoxin on the uptake of ${ }^{86} \mathrm{Rb}$ by normal human red cells in vitro, and demonstrated the feasibility of assaying the concentration of cardiac gylcosides in human plasma by such a method.

The purpose of the present investigation has been to develop this method further and to see whether the concentration of digoxin in plasma can be used as an aid in the diagnosis of digoxin intoxication.

\section{Materials and Methods}

Modified Krebs-Ringer phosphate solution was made up as follows: $0.9 \% \mathrm{NaCl}, 1$ 1. ; $1.22 \% \mathrm{CaCl}_{2}, 15 \mathrm{ml}$. ; $3.82 \%$ MgSO $.7 \mathrm{H}_{2} \mathrm{O}, 10 \mathrm{ml}$. ; $0 \cdot 1 \mathrm{M}$ phosphate buffer, $\mathrm{pH} 7 \cdot 4$ (17.8 g. $\mathrm{Na}_{2} \mathrm{HPO}_{4} .2 \mathrm{H}_{2} \mathrm{O}+20 \mathrm{ml}$. $N \mathrm{HCl}$ diluted to 11 .), $210 \mathrm{ml} .100$ mg. of glucose was added to each $100 \mathrm{ml}$. of this solution before use.

* Senior Lecturer in Applied Pharmacology and Therapeutics. Honurary Consultant Physician, Medical Unit, St. Mary's Hospital, London W.2.

† Senior Medical Registrar, St. Mary's Hospital, London W.2.
Rubidium chloride ${ }^{86} \mathrm{RbCl}$ ) was obtained from the Radiochemical Centre, Amersham, England, and diluted to $2.2 \mathrm{mM}$ (initial specific activity $0.067 \mu \mathrm{mole} / \mu \mathrm{Ci}$ ) with $\mathrm{Krebs}-$ Ringer phosphate solution.

Preparation of Human Red Cells.-Venous blood was taken from normal subjects in a syringe rinsed with heparin $(5,000$ $\mathrm{u} . / \mathrm{ml}$.). The blood was centrifuged at $1,000 \mathrm{~g}$ for 10 minutes at $5^{\circ} \mathrm{C}$. and the plasma and top layer of cells were removed by suction. The red cells were then washed twice with ice-cold Krebs-Ringer phosphate solution by alternate resuspension and spinning. After the final spin the supernatant was removed and the packed cells were gently mixed and kept at $5^{\circ} \mathrm{C}$. until used (not longer than four hours).

Extraction of Digoxin from Plasma. $-5 \mathrm{ml}$. of heparinized plasma was vigorously shaken with $10 \mathrm{ml}$. of methylene chloride for two minutes in a stoppered glass tube and the tube centrifuged at $1,500 \mathrm{~g}$ for 10 minutes. The upper aqueous layer and the thick lipid interface were removed by suction. About $1 \mathrm{~g}$. of anhydrous $\mathrm{Na}_{2} \mathrm{SO}_{4}$ was added to the remainder. The tube was vigorously shaken for 20 seconds and then briefly centrifuged. Of the clear methylene chloride $5 \mathrm{ml}$. was pipetted into a round-bottomed tube (16 by $125 \mathrm{~mm}$.). The methylene chloride was evaporated to dryness in a stream of air at $45^{\circ} \mathrm{C}$.

Incubation.-The dried extract was well mixed with $0.3 \mathrm{ml}$. of Krebs-Ringer phosphate solution and $0.2 \mathrm{ml}$. of prepared packed human red cells added. The suspension was incubated for 45 minutes at $36^{\circ} \mathrm{C}$. with gentle shaking in air. Then $0.1 \mathrm{ml}$. of $2.2 \mathrm{mM}{ }^{86} \mathrm{RbCl}$ was added and incubation continued under the same conditions for a further two hours. The final volume of the incubation sample was $0.6 \mathrm{ml}$., and the concentration of ${ }^{86} \mathrm{RbCl}$ was $0.37 \mathrm{mM}$.

Preparation of Sample for Radioactive Assay.-At the end of the incubation $10 \mathrm{ml}$. of ice-cold $0.154 \mathrm{M} \mathrm{NaCl}$ was added with mixing. The sample was centrifuged at $1,500 \mathrm{~g}$ for 10 minutes at $5^{\circ} \mathrm{C}$., the supernatant being removed by suction. The red cells were washed twice with $10-\mathrm{ml}$. volumes of icecold $0.154 \mathrm{M} \mathrm{NaCl}$ by alternate resuspension and centrifugation. After the final spin the supernatant was removed from the red cells as completely as possible. The packed red cells were then assayed for radioactivity in a scintillation-well system to detect the $1.08 \mathrm{meV} \gamma$-emission of ${ }^{86} \mathrm{Rb}$ at an efficiency of $10 \%$. When the ${ }^{86} \mathrm{RbCl}$ was received the specific activity was 